\begin{tabular}{|l|l|l|l|l|l|}
\hline J. Tek. Ling. & Vol. 10 & No. 1 & Hal. 85 - 89 & Jakarta, Januari 2009 & ISSN 1441-318X \\
\hline
\end{tabular}

\title{
PENGOLAHAN LIMBAH CAIR INDUSTRI MINUMAN RINGAN
}

\author{
Indriyati dan Joko Prayitno Susanto \\ Peneliti di Pusat Teknologi Lingkungan \\ Badan Pengkajian dan Penerapan Teknologi
}

\begin{abstract}
The concentration of soft drink contains organic waste water not so high. There fore one of the alternative of processing technology is used aerobic system: Oxydation ditch. On this observation can be seen that the system is able to degrade the organic matter by observe the operation parameters process to operate the system and the parameters are BOD, COD, TSS, Oil \& grease, TDS, Total N and $\mathrm{pH}$. All parameters show stability process during 3 (three) months operation. Base on the criteria as mentioned above, the efficiency that can be reached by this system are around $96,875 \%$ for BOD efficiency, COD $96 \%$ for COD efficiency, TSS $80 \%$, Oil \& grease $75 \%$, Total N 76,92\% and pH $41 \%$.
\end{abstract}

Keywords: limbah cair, minuman ringan

\section{PENDAHULUAN}

Perkembangan industri dan teknologi di berbagai bidang kehidupan selain meningkatkan kualitas hidup manusia juga memberikan dampak lain terhadap kelangsungan lingkungan hidup yaitu berupa pencemaran. Untuk mencegah terjadinya pencemaran lingkungan yang tidak diinginkan, maka pemerintah mengeluarkan suatu standar baku mutu untuk buangan limbah, khususnya untuk limbah cair cukup ketat, sehingga mendorong pelaku-pelaku industri untuk mencari dan menggunakan teknologi pengolahan limbah yang ekonomis dan berdaya guna tinggi.

Salah satu industri minuman dengan berbagai rasa, menggunakan gula dan glukosa sebagai bahan baku utama, sehingga limbah yang dihasilkan mengandung bahan organik yang cukup tinggi berkisar antara $500-3000$ mg/l dan dalam pengolahannya menggunakan sistem aerob dengan menggunakan Baku mutu limbah cair yang dikeluarkan oleh Keputusan Menteri Negara Lingkungan Hidup No. KEP51/MENKLH/10/1995 tanggal 23 Oktober 1995 untuk kegiatan industri, konsentrasi COD maksimum yang diperbolehkan untuk golongan I adalah $100 \mathrm{mg} / \mathrm{l}$.

Tujuan pengamatan ini adalah melakukan pemantauan terhadap nilai yang dicapai oleh parameter-parameter proses pengolahan limbah cair pabrik minuman ringan dengan sistem Oxydation ditch, sehingga dapat memenuhi baku mutu limbah cair untuk golongan I. Pengamatan ini dilakukan selama 3 (tiga) bulan dengan memperhatikan parameter proses limbah cair yang masuk kepengolahan (inlet) dan limbah cair yang keluar dari pengolahan (efluen). 


\section{TINJAUAN PUSTAKA}

Teknologi pengolahan limbah cair dapat diklasifikasikan ke dalam tiga metode yaitu pengolahan fisik, kimia dan biologi. Penerapan masing-masing metode tergantung pada kualitas air baku dan kondisi fasilitas yang tersedia ${ }^{1}$. Prinsip pengolahan biologis adalah menyisihkan senyawa organik terlarut, yang melibatkan mikroba aktif untuk kontak dengan air limbah, agar mikroba tersebut dapat mengkonsumsi impuritas (pencemar) sebagai makanannya ${ }^{2}$. Dalam mengklasifikasikan proses pengolahan biologis aerobik berdasarkan media pertumbuhannya secara garis besar dibagi 3 (tiga) macam, yaitu :

1). Proses Biomasa Tersuspensi (Suspended Culture).

- Conventinal/standard Activated Sludge

- Step Aeration

- Contact Stabilization

- Oxidation Ditch

- Lain-lain

2). Proses Biomasa Terlekat (Attached Culture).

- Trickling Filter/Biofilter

- Rotating blological Contactor (RBC)

- Contact Oxidation

- Lain-lain

\section{3). Kolam (lagoon).}

Sistem pengolahan yang digunakan untuk menurunkan BOD dan COD adalah pengolahan biologi dengan menggunakan Lumpur aktif (activated sludge) yang dilakukan di dalam Oxydation Ditch. Lumpur Aktif (Activated Sludge) adalah termasuk pengolahan biologi dengan biomassa tersuspensi, dalam proses lumpur aktif, mikroorganisme (MO) dicampur dengan senyawa organik sehingga $\mathrm{MO}$ tersebut dapat tumbuh dan menstabilkan senyawa organik ${ }^{2}$. Bagian-bagian penting yang terintegrasi dalam Unit Lumpur Aktif adalah:

a. Sub unit Bak Aerasi : sebagai wadah bercampurnya dan bereaksinya elemen reaksi seperti mikroba, organik terurai dan oksigen

b. Sub unit Bak Pengendap : tempat pemisahan lumpur aktif secara gravitasi

c. Sistem Pengendali Lumpur : untuk mengontrol besarnya debit lumpur yang diresirkulasi (RAS) dan lumpur yang dibuang (WAS).

Oxidation Ditch (oksidasi parit) adalah Reaktor berupa parit atau saluran panjang berbentuk oval yang dilengkapi satu atau lebih rotor rotasi untuk aerasi limbah. Efluen dijernihkan dan lumpur yang mengendap dikembalikan ke reaktor untuk menjaga konsentrasi MLSS ${ }^{2}$ Effisiensi penyisihannya berkisar antara $75-95 \%{ }^{3)}$

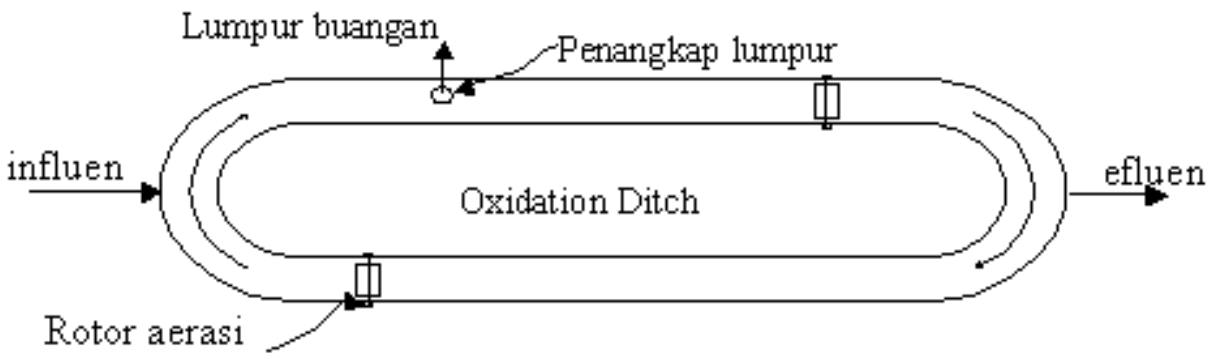

Gambar 1. Reactor oxidation ditch 


\subsection{Sistem aliran dalam reaktor}

- Plug-flow, air limbah dilewatkan ke dalam reaktor dan keluar dengan rangkaian yang sama pada saat masuk.

- Complete-mix atau continous stirred tank reactors (CSTR), air limbah yang masuk didispersikan dengan segera ke seluruh bak/tangki dengan aliran kontinyu, sehingga organic loading (OL) dan oksigen merata di seluruh tangki.

- Arbitrary-flow, adalah tipe reaktor dengan aliran yang dapat diubah antara plug-flow dan complete-mix

\subsection{Aplikasi Proses dan Modifikasi Lumpur Aktif}

Lumpur aktif konvensional adalah dengan melakukan pengadukan dan aerasi air limbah dalam bak panjang dan sempit. Permasalahan yang timbul adalah

1). Biomassa yang diresirkulasi ke awal tangki dan bercampur dengan air limbah akan menyebabkan kebutuhan oksigen melebihi kemampuan dari kapasitas energi.

2). Pada bagian sekitar outlet oksigen yang dibutuhkan relatif kecil.

3). Kegagalan proses akibat shock loading dari senyawa toksik atau tinggi yang disebabkan oleh beban yang tidak merata ke seluruh tangki, tapi sangat terkonsentrasi ke daerah awal tangki/ inlet.

\section{METODOLOGI PENELITIAN}

Pelaksanan pengamatan dilakukan dalam 3 (tiga) bulan berturut-turut dengan memperhatikan parameter BOD, COD, TSS, oil pada grease, TDS, total $\mathrm{N}$, dan $\mathrm{pH}$ limbah cair. yang masuk ke dalam dan keluar sistem. Pengukuran parameter dilakukan terhadap limbah cair yang keluar dari pabrik sebelum masuk ke dalam sistem sebelum bar screen, kemudian dilakukan pada tangki Oxydatich I dan keluaran efluen dari Oxydation Ditch II. Proses yang dilakukan pada pengolahan limbah cair minuman ringan dimulai dengan limbah cair $^{4)}$ dari proses pembersihan di pabrik dialirkan menuju peralatan pengolah limbah yang terdiri dari

1). Bar screen.

Bar screen digunakan untuk menyaring semua sampah dan seal botol, plastik, sedotan dan lain-lain agar tidak terbawa aliran air limbah yang masuk ke unit pengolahan.

2). Grease Trap.

Grease trap dibuat dengan volume tertentu sehingga aliran air diperlambat untuk memberi kesempatan minyak yang terkandung dalam air limbah untuk memisahkan diri dari air.

3). Sump Pit

Sump pit merupakan tempat diletakkannya pompa yang digunakan untuk mengalirkan air limbah ke Equalization basin.

4). Cooling Tower \& Cooling Tower Tank.

Cooling tower Tank digunakan untuk menurunkan suhu limbah yang dilengkapi dengan 2 buah pompa transfer yang akan mempompa air limbah ke Neutralisasi Tank.

5). Neutralisasi Tank

Pengolahan limbah yang menggunakan proses biologi (proses lumpur aktif) akan berjalan optimal pada $\mathrm{pH}$ sekitar 7 - 8,5 dan mengingat air limbah mempunyai $\mathrm{pH} 11$ - 12 (basa_ maka perlu dilakukan pengaturan $\mathrm{p} \overline{\mathrm{H}}$ ini dengan penambahan asam chlorida ( $\mathrm{HCl})$ di neutralisasi tank yang dilengkapi dengan mixer.

6). Oxidation ditch - I dan II.

Oxidation ditch merupakan tempat utama berlangsungnya proses mikrobiologi dengan menggunakan lumpur aktif. Kandungan senyawa 
organik diharapkan akan terdegradasi kurang lebih 90\% dengan bantuan bakteri selain itu terjadi juga proses nitrifikasi dan denitrifikasi. Unit pengolahan didesain dalam 2 tahap untuk penurunan BOD secara seri. Pada Oxydation I diharapkan BOD turun dari 1600 ppm menjadi 700 ppm dan pada Oxydation Dicth II dari 700 ppm menjadi 50 ppm.

7). Tube settler.

Masa bakteri/ lumpur yang berasal dari Oxydation Ditch harus dipisahkan dari air limbah dengan cara pengendapan gravitasi di Tube Settler. Lumpur / massa bakteri akan mengendap di bagian bawah Tube Settler dan mengalir ke Sludge Collector, sedangkan air limbah akan mengalir mengalir secara gravitasi menuju Control tank.

8). Sludge colector.

Sludge colector merupakan tempat penampungan sementara lumpur cair yang berasal dari Tube Settler I \& II. Sludge Colector dilengkapi dengan dua pompa yang dapat bekerja bergantian secara otomatis maupun manual untuk memompa lumpur cair untuk didaur ulang kembali (recycle) ke Oxydation Ditch atau dialirkan ke Decanter untuk dikeringkan.

9). Decanter

Lumpur cair yang berasal dari Sludge Colector akan diperkecil kadar airnya dengan menggunakan decanter. Salah satu kelebihan decanter adalah dapat bekerja secara terus menerus, dengan memanfaatkan gaya centrifugal maka lumpur yang masuk akan terpisah dari air. Air yang sudah terpisah dari lumpur dialirkan ke Control Tank, sedangkan partikel padatan akan keluar melalui outlet lumpur.

Perancangan unit pengolahan air limbah yang ada dilakukan berdasarkan kualitas air limbah yang akan diolah dan banyaknya air limbah yang harus diolah. Proses dapat dikatakan berjalan baik atau optimal bilamana parameter-parameter di setiap tangki tidak melebihi atau kurang dari parameter desain pengolahan limbah cair.

\section{ANALISA HASIL}

Volume limbah cair yang diolah sebanyak $15 \mathrm{~m} 3 /$ jam atau $360 \mathrm{~m} 3 /$ hari. Sistem pengolahan yang digunakan untuk menurunkan BOD dan COD adalah pengolahan biologi dengan menggunakan lumpur actif (activated sludge) yang dilakukan di dalam Oxydation Ditch. Parameter air limbah seperti TDS akan tetap sama konsentrasinya sebelum dan sesudah diolah. Kadar TDS dari limbah cair sebelum dan sesudah pengolahan sudah dibawah dibawah baku mutu, jadi tidak diperlukan pengolahan lagi.

Berdasarkan pengamatan yang dilakukan selama 3 (tiga bulan) didapat hasil seperti terlihat pada Tabel 1.

Tabel 2. Hasil proses pengolahan pada unit system

\begin{tabular}{|l|c|c|c|}
\hline \multicolumn{1}{|c|}{ Parameter } & Awal & Oxydation I & Oxydation II \\
\hline BOD & $1600 \mathrm{ppm}$ & $700 \mathrm{ppm}$ & $50 \mathrm{ppm}$ \\
\hline COD & $2500 \mathrm{ppm}$ & $250 \mathrm{ppm}$ & $100 \mathrm{ppm}$ \\
\hline TSS max & $300 \mathrm{ppm}$ & $100 \mathrm{ppm}$ & 60 \\
\hline Oil dan grease max & $20 \mathrm{ppm}$ & $10 \mathrm{ppm}$ & 5 \\
\hline TDS max & $1200 \mathrm{ppm}$ & $1200 \mathrm{ppm}$ & $1200 \mathrm{ppm}$ \\
\hline Total $\mathrm{N} \max$ & $13 \mathrm{ppm}$ & $5 \mathrm{ppm}$ & $3 \mathrm{ppm}$ \\
\hline $\mathrm{pH} \max$ & $10-11$ & $7,0-8,5$ & $6,5-8,5$ \\
\hline Temp max & $35^{\circ} \mathrm{C}$ & $29^{\circ} \mathrm{C}$ \\
\hline
\end{tabular}


Berdasarkan hasil data pengamatan selama 3 (tiga) bulan terlihat adanya penurunan dari parameter - parameter selama pengolahan sehingga dapat memenuhi baku mutu yang disyaratkan. Penurunan BOD pada tangki Oxidation I terjadi sebesar $56,25 \%$ untuk tangki Oxydation Ditch II terjadi penurunan sebesar $96,875 \%$ dari yang pertama, parameter COD memperlihatkan penurunan $90 \%$ untuk yang pertama dan $96 \%$ untuk yang kedua, TSS berkurang $66,7 \%$ untuk yang pertama dan $80 \%$ untuk yang kedua, Oil \& grease menurun $50 \%$ dan $75 \%$ untuk yang kedua, sedangkan TDS nya tetap karena sudah dibawah baku mutu yang disyaratkan, untuk Total $\mathrm{N}$ terjadi penurunan $61,5 \%$ pada tangki Oxydation Ditch I dan 76,92 \% untuk yang kedua sedangkan untuk penurunan temperatur relatif stabil penurunannya tidak terlalu tinggi karena limbah cair yang keluar cukup hangat dan temperatur ambient cukup panas.

\section{KESIMPULAN}

Berdasarkan pengamatan yang dilakukan selama tiga bulan dapat diambil kesimpulan sebagai berikut :

1). Unit pengolah limbah dengan sistem Oxydation Ditch dalam activated sludge dapat digunakan untuk pengolahan limbah cair dari pabrik minuman ringan sejenis dengan kandungan BOD yang tidak terlalu tinggi serta efisiensi yang dicapai sebesar $96,875 \%$, COD $96 \%$, TSS $80 \%$, Oil \& grease $75 \%$, TDS tetap 1200 ppm karena sudah dibawah baku mutu, Total N 76,92 \%, pH turun sekitar $41 \%$ sedangkan temperatur turun menjadi $29^{\circ} \mathrm{C}$

2). Parameter - parameter desain yang menjadi kriteria desain unit pengolah limbah dapat dipenuhi oleh parameter-parameter selama pengoperasian unit tersebut.

\section{DAFTAR PUSTAKA.}

1. Qasim, Syed R, Wastewater Treatment Plants - Planning, Design, and Operation, CBS College Publishing, New York, 1985.

2. Hammer, Mark J, Water and Wastewater Technology, John Wiley \& Sons, Inc., New York, 1975.

3. Metcalf-Eddy, Wastewater Engineering Treatment Disposal and Reuse, McGraw-Hill inc., New York, 1991.

4. Djayadiningrat, Asis $\mathrm{H}$. dan Wisjnuprapto, Bioreaktor Pengolah Limbah Cair, Pusat Antar UniversitasITB, Bandung, 1990. 